\section{Is Posterior Reversible Encephalopathy Syndrome Underestimated in Systemic Lupus Erythematosus?}

\section{To the Editor:}

Varaprasad and colleagues described a cohort of reversible encephalopathy in patients with systemic lupus erythematosus (SLE) ${ }^{1}$. This cohort adds to the increasing evidence that SLE can manifest reversible encephalopathy, e.g., posterior reversible encephalopathy syndrome (PRES) ${ }^{2,3}$. It is possible that PRES is underestimated in SLE. However, we are concerned about the differential diagnoses of these cases.

PRES, also termed reversible posterior leukoencephalopathy syndrome, was initially described by Hinchey, et $a l^{4}$ in 1996 as a clinico-radiological entity characterized by typical neurological deficits (headache, nausea and vomiting, altered mental status, visual impairment, and seizures), transient radiological brain anomalies, and a usually self-limited, benign and reversible clinical course. Different conditions might be attributable, such as eclampsia, hypertensive encephalopathy, renal diseases with hypertension, use of cyclosporine A or other immunosuppressive drugs ${ }^{5,6}$, etc. Other rare pathophysiological conditions, such as intracranial hypotension, have also been documented.

The pathophysiological mechanism of PRES is suggested to be vasogenic edema, arising from failure of cerebrovascular autoregulation and disruption of the blood-brain barrier ${ }^{7}$. Although signal hyperintensity can be seen in magnetic resonance imaging (MRI), and T2-weighted imaging and fluid-attenuated inversion recovery images may show abnormal signal intensity, diffusion-weighted imaging (DWI) and apparent diffusion coefficient (ADC) maps are indispensable to differentiate vasogenic edema in PRES from cytotoxic edema as well as ischemia ${ }^{8}$.

Central nervous system (CNS) involvement in SLE is common. It can include vasculitis ${ }^{9}$, acute or subacute infarction ${ }^{10}$, and PRES ${ }^{2,3}$. Either lupus vasculitis or PRES may present with reversible lesions in the CNS. Therefore, reversible vasogenic edema as revealed by DWI and ADC maps, preferably involving the posterior white matter, can differentiate PRES from other reversible pathological changes in the CNS. For those patients with SLE who have neuropsychiatric manifestations, e.g., seizures, the reversible clinical symptoms and MRI anomalies may arise from epileptic seizures per se, rather than PRES. Since a well acknowledged set of diagnostic criteria for PRES is lacking, we wonder whether the authors considered other SLE-associated reversible lesions as the differential diagnoses. A failure to do so may lead to an overestimation of PRES in SLE.

PRES does appear to be underestimated in SLE. However, the diagnosis of PRES might be confounded by other reversible pathological changes in SLE.
XIAO-KE WANG, MD, Department of Neurosurgery, Second Hospital of Jilin University; HONGLIANG ZHANG, MD, Department of Neurology, First Hospital of Jilin University, Xinmin Street 71, 130021, Changchun, China. Address correspondence to Dr. Zhang; E-mail:drzhl@hotmail.com.

\section{REFERENCES}

1. Varaprasad IR, Agrawal S, Prabu VN, Rajasekhar L, Kanikannan MA, Narsimulu G. Posterior reversible encephalopathy syndrome in systemic lupus erythematosus. J Rheumatol 2011;38:1607-11.

2. Kur JK, Esdaile JM. Posterior reversible encephalopathy syndrome - an underrecognized manifestation of systemic lupus erythematosus. J Rheumatol 2006;33:2178-83.

3. Bag AK, Curé JK, Sullivan JC, Roberson GH. Central variant of posterior reversible encephalopathy syndrome in systemic lupus erythematosus: new associations? Lupus 2010;19:225-6.

4. Hinchey J, Chaves C, Appignani B, Breen J, Pao L, Wang A, et al A reversible posterior encephalopathy syndrome. N Engl J Med 1996;334:494-500.

5. Sharma M, Kupferman JC, Brosgol Y, Paterno K, Goodman S, Prohovnik I, et al. The effects of hypertension on the paediatric brain: a justifiable concern. Lancet Neurol 2010;9:933-40.

6. Rubin AM, Kang H. Cerebral blindness and encephalopathy with cyclosporin A toxicity. Neurology 1987;37:1072-6.

7. Lee VH, Wijdicks EF, Manno EM, Rabinstein AA. Clinical spectrum of reversible posterior leukoencephalopathy syndrome. Arch Neurol 2008;65:205-10.

8. Zhang HL, Yang Y, Zhou HW, Wu J. Diagnosis of posterior reversible encephalopathy syndrome: Does DWI help? Lancet Neurology 2010;9:1046-7.

9. Nikolov NP, Smith JA, Patronas NJ, Illei GG. Diagnosis and treatment of vasculitis of the central nervous system in a patient with systemic lupus erythematosus. Nat Clin Pract Rheumatol 2006;2:627-33

10. Moritani T, Shrier DA, Numaguchi Y, Takahashi C, Yano T, Nakai $\mathrm{K}$, et al. Diffusion-weighted echo-planar MR imaging of CNS involvement in systemic lupus erythematosus. Acad Radiol $2001: 8: 741-53$

J Rheumatol 2011;38:11; doi:10.3899/jrheum.110762 